\title{
Attraction to mobile and immobile conspecifics
}

\author{
D. H. THOR, K. L. WAINWRIGHT, and W. R. HOLLOWAY \\ Edward R. Johnstone Training and Research Center, Bordentown, New Jersey 08505
}

\begin{abstract}
Male and female laboratory rats invariably investigate a novel conspecific placed in their home cages. In Experiment 1, mature male rats were exposed in their home cages to active and inactive juvenile males. Inactive juveniles were pretreated with haloperidol to induce behavioral stasis in a normally upright, quadrupedal stance. In repeated daily observations, males exposed to active juveniles displayed significantly longer intervals of investigation than did males exposed to inactive juveniles. In Experiment 2, mature males and females were repeatedly exposed to active and inactive castrate females. Males investigated significantly longer than did females, active female castrates were investigated significantly longer than were inactive female castrates, and sex of subject interacted significantly with activity. nonactivity of the social stimulus animal. In Experiment 3, mature males and females were repeatedly exposed to active and inactive castrate males. Males investigated significantly longer than did females, active male castrates were investigated significantly longer than were inactive male castrates, and sex of subject interacted significantly with activity-nonactivity of the social stimulus animal. The results demonstrate that sexual dimorphism in persistence of social investigation may be interpreted as a sex difference in response to normal movement cues of a stimulus complex characterizing a conspecific.
\end{abstract}

Social attraction evidently serves important biological functions, and an unfamiliar conspecific normally constitutes an attractive social stimulus (Latané \& Hothersall, 1972). In the rat, olfactory cues may serve to indicate sex, maturity, and individual identity (Carr, 1974; Carr, Demesquita-Wander, Sachs, \& Maconi, 1979; Carr, Hirsch, \& Balazs, 1980). Movement may also contribute substantially to attractive qualities by dispersing odors and by constituting a signal for social interaction (Latané, Joy, Meltzer, Lubell, \& Cappell, 1972). Learned predispositions to react sexually or aggressively to a set of odor and movement cues have been suggested by a number of behavioral investigations (Beach, 1976; Brown, 1979; Sachs \& Barfield, 1976).

Sex differences in social investigation of a conspecific prior to a criterion of neglect have recently been demonstrated (Thor, 1980b). Males investigate a novel juvenile for significantly longer intervals than do females (see also Meaney \& Stewart, 1979). In the present experiments, social stimulus animals were presented in their normally active condition and in a drug-induced immobile condition. It was hypothesized that male subjects would investigate a normally active conspecific for longer intervals than would female subjects and that an inactive conspecific would fail to elicit a sex difference in time of investigation prior to a criterion of neglect.

\section{EXPERIMENT 1}

Immobile postures are occasionally assumed by male and female rats threatened or attacked by a dominant rat. Sustained immobility in a normal up- right stance can also be achieved by a large dose of haloperidol; a detailed description of such druginduced stasis is available elsewhere (Thor \& Flannelly, 1978, p. 334). The present experiment was conducted to determine whether movement or movementassociated cues of a novel conspecific have a significant effect on duration of investigation time by a mature male subject prior to a criterion of neglect.

\section{Method}

Subjects and Apparatus. Sixteen laboratory-reared male LongEvans rats, 6-8 months of age, served as subjects. Two groups of eight were formed and assigned to two test conditions. Sixteen juveniles, 20-30 days of age, were used as social stimuli. Each subject was tested, after $24 \mathrm{~h}$ of isolation in the home cage $(41 \times 55 \times 22 \mathrm{~cm})$, by exposure to a juvenile in the subject's home cage.

Logic modules were used to time switch closures and to signal the end of a test. An operations recorder was used to provide a tape record of investigatory bout duration by each subject. Total investigation time was obtained by summating all investigatory bout durations during each test.

Procedure. One group of eight male subjects were individually exposed to immobile juveniles, and the other group of male subjects were individually exposed to normally active juveniles. The inactive state was induced by a $5-\mathrm{mg} / \mathrm{kg}$ dose of haloperidol (Haldol, McNeil Laboratories) given about $30 \mathrm{~min}$ before testing. The stimulus animal was placed in the center of the subject's home cage, and duration of active social-investigatory behavior (sniffing, nosing, grooming, or following -in contact with or nares within $2 \mathrm{~cm}$ of juvenile) was recorded until no further investigatory behavior occurred for an interval of $30 \mathrm{sec}$ (hereafter referred to as the neglect criterion). The test was then terminated, and the juvenile stimulus was removed. Subjects were tested daily, at the same time of day, for 3 consecutive days in normal room illumination (overhead fluorescent lamps). The observer was normally positioned about $1 \mathrm{~m}$ from the translucent plastic cage. Each male group was tested with only one category of social stimuli (i.e., active or inactive juveniles). 
Table 1

Means and Standard Errors of Investigation Time by Mature Males Exposed to Active or Inactive Juveniles

\begin{tabular}{|c|c|c|c|c|c|c|}
\hline \multirow{2}{*}{$\begin{array}{c}\text { Juvenile } \\
\text { Condition }\end{array}$} & \multicolumn{2}{|c|}{ Test 1} & \multicolumn{2}{|c|}{ Test 2} & \multicolumn{2}{|c|}{ Test 3} \\
\hline & Mean & $\mathrm{SE}$ & Mean & $\mathrm{SE}$ & Mean & $\mathrm{SE}$ \\
\hline Active & 124.1 & 15.1 & 108.4 & 11.7 & 129.8 & 23.0 \\
\hline Inactive & 27.1 & 5.1 & 41.8 & 6.8 & 49.5 & 9.1 \\
\hline
\end{tabular}

Note-All measures are given in seconds.

\section{Results and Discussion}

Means and standard errors of the data are presented in Table 1. Total investigation time data were given a square-root transformation to reduce the effect of extreme scores and to stabilize the variance. A two-way analysis of variance (groups $\times$ tests) revealed a significant difference between groups $[F(1,14)$ $=56.05, \mathrm{p}<.001 \mathrm{]}$, a nonsignificant effect of repeated tests, and a nonsignificant interaction. Oneway analyses for repeated measures within groups were nonsignificant.

These results may be interpreted as indicating a reliable difference in male investigation time of active and inactive juveniles prior to the neglect criterion. Lack of significant differences within groups over repeated daily testing suggests that the test is a stable measure when used at 24-h intervals (see Latané, Nesbitt, Eckman, \& Rodin, 1972, for a discussion of the "state of social deprivation" and relative influence of social deprivation and social satiation on gregariousness).

\section{EXPERIMENT 2}

This experiment was conducted to determine whether activity-inactivity of a novel conspecific interacts with sex of the subject. If activity is a significant component of social stimulation, as suggested by the results of Experiment 1, then there may well exist a significant sex difference in response to social activity by males and females that contributes, at least in part, to the distinctive sex difference in persistence of social investigation described elsewhere (Thor, 1980b). This line of reasoning is compatible with the general hypothesis of sex differences in spatial information processing of rats (Beatty, 1979, p. 141).

\section{Method}

Subjects. Eight males and eight females of the Long-Evans strain, 70-80 days old, were used as subjects. Since having been weaned at 25 days of age, all had been maintained in like-sex groups of four per cage. Twelve mature females, castrated at 40-45 days of age, were used as social stimuli. Preliminary observations suggested longer intervals of initial investigatory behavior with castrate females than with juveniles and, consequently, a potentially more sensitive measure of interactive effects.

Apparatus and Procedure. The apparatus was expanded to record three categories of observation - namely, investigation (sniff- ing, following, nosing, or grooming), copulatory mounting, and aggression. Duration of each behavior was recorded by depression of switches on a hand-held switch console. Any contact with the switch reset a 30-sec countdown timing circuit that restarted upon release of the switch. Completion of the $30-\mathrm{sec}$ countdown activated a brief tone that signaled the neglect criterion and the termination of the observation trial. All observations were made in dim red light (a $40-\mathrm{W}$ incandescent red lamp located about $3 \mathrm{~m}$ from cages). The observer was positioned about $1 \mathrm{~m}$ from the translucent plastic front of the subject's home cage. The vigorous and sustained social investigation by subjects suggested that presence of the observer had a minor influence, if any, on the subjects' social investigation of the intruder. Termination of investigative behavior was normally followed by self-grooming behavior.

Each subject was tested once per day at the same time of day (during the normally dark phase) for 6 days. Half of the subjects of each sex were exposed to normally active female castrates on each of the first 3 days and to haloperidol-treated female castrates on each of the following 3 days. The remaining subjects were exposed to haloperidol-treated female castrates on each of the first 3 days and to normally active female castrates on each of the following 3 days. Thus, order of exposure to social stimuli was counterbalanced.

Haloperidol-treated female castrates received a dosage sufficient to suspend normal movement (i.e., ambulation, limb movement, and head movement). Initially, $5 \mathrm{mg} / \mathrm{kg}$ was given ip, and occasionally a supplementary dose was given if any body movement was observed after $30 \mathrm{~min}$. One nontreated and one treated mature female castrate were used for all exposures on each day. Each observation began when the stimulus female was placed in the center of the subject's cage.

\section{Results and Discussion}

Medians of the three daily tests for each subject on each category of social stimulus (active or inactive) were used to decrease variance attributable to occasional extremely high or low measures. None of the females mounted, and males averaged only $1 \mathrm{sec}$ of mounting on inactive castrate females and $4 \mathrm{sec}$ of mounting on active castrate females. Similarly, only three males and two females displayed any aggressive behavior. Therefore, copulatory mounting and aggression times were excluded from further analysis. One female subject displayed proceptive behaviors (hopping and darting) toward the stimulus animal and was retested the following day.

The bulk of observed behavior $(\mathbf{9 2 \%})$ consisted of social investigation. Means and standard errors of investigation time for males and females presented with active or inactive castrate females are given in Figure 1. The main effect of order and the interactions of order with the other variables were nonsignificant. The analysis of variance indicated a significant effect for sex of the subject $[F(1,12)=52.68, p<.001]$, with males investigating more than twice as long as females. The activity of the stimulus female also influenced investigation time $[F(1,12)=16.65, p<$ .005 , with active castrates being investigated more than twice as long as inactive castrates. The interaction of sex $\times$ activity was also significant $[F(1,12)$ $=5.39, p<.05]$. 


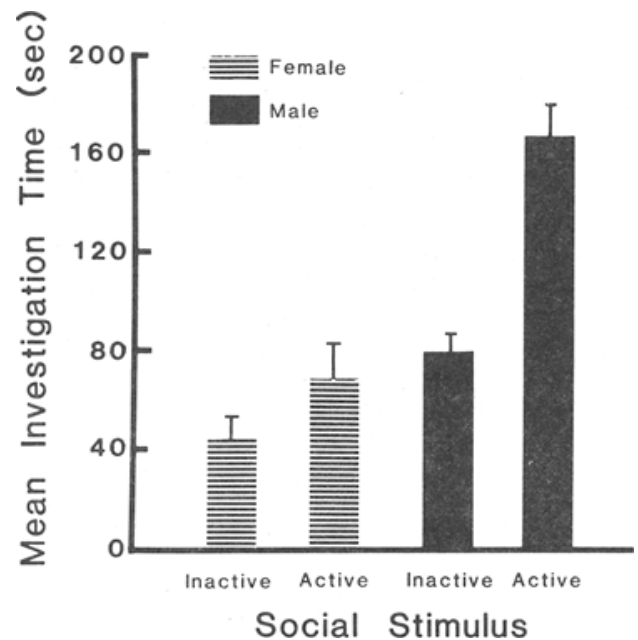

Figure 1. Means and standard errors of investigation times by male and female groups exposed to active and inactive mature female castrates.

The results confirm the presence of a sex difference in persistence of social investigation and further show that an immobile stimulus animal is investigated by male subjects only about half as much as a mobile stimulus animal (comparable to the difference observed in Experiment 1). Of particular interest, however, is the significant interaction; that is, male subjects are apparently more influenced by mobility than are female subjects. A correlated t test indicated a nonsignificant mean difference in female investigation of active and inactive stimuli, although the mean investigation time of active stimuli was about $24 \mathrm{sec}$ longer than that of inactive stimuli. A correlated $t$ test of the investigation times of males indicated a significant mean difference in the investigation of active and inactive stimuli $[t(7)=10.31$, $\mathrm{p}<.001]$. A t test indicated that the difference in mean investigation times of males exposed to normally active castrate females (Experiment 2) and males exposed to normally active juveniles (Experiment 1) was nonsignificant $(p>.05)$. Males investigated inactive castrate females, however, significantly longer than they investigated inactive juveniles $[\mathrm{t}(14)=4.98, \mathrm{p}<.01]$.

\section{EXPERIMENT 3}

This experiment was conducted to determine whether the response by male and female subjects to active and inactive male stimulus animals is comparable to that observed with female stimulus animals in Experiment 2. It was hypothesized, on the basis of the distinctive influence of the activityinactivity variable observed in Experiment 1 with juvenile stimulus animals, that male subjects would investigate normally active, mature castrate males significantly longer than they would investigate inactive, mature castrate males, and that this difference would be significantly greater for male subjects than for female subjects (i.e., that sex of subject interacts significantly with the active or inactive state of the stimulus animal). Castrates were used as social stimuli to decrease copulatory and aggressive interactions with the subjects.

\section{Method \\ Subjects. Sixteen additional laboratory-reared male and female subjects were used. All were experimentally and sexually naive and were 80-90 days of age. Twelve males, castrated at 35 days of age and approximately 75 days of age at the time of testing, were used as social stimuli. \\ Apparatus and Procedure. The apparatus and procedure were the same as those in Experiment 2. Any female displaying any} indication of sexual receptivity was retested the following day.

\section{Results and Discussion}

Medians of the three daily tests for each subject on each category of social stimulus (active or inactive male castrate) were used in all analyses to decrease variance attributable to occasional extreme scores. Male subjects occasionally mounted the stimulus males, but these data were insufficient for statistical analysis. Only two females displayed any aggressive behavior, so this category of data was also dropped.

As in Experiment 2, the initial response to the male castrates was that of intense investigatory behavior, and the pattern of response by sex of subject was comparable to that observed with female stimulus animals in Experiment 2. A three-way analysis of variance indicated no significant main effect of order and a significant main effect for duration of investigation by sex of subject $[F(1,12)=12.16, p<.01]$, with males persisting longer than females. Active stimulus males were investigated significantly longer than were inactive males $[F(1,12)=39.54, p<.001]$, and the interaction of sex $\times$ activity was significant $[F(1,12)=22.61, p<.001]$. Male subjects investigated active stimulus animals more than twice as long as did female subjects. Means and variances of investigative behavior by sex of subject and activity of stimulus animal are given in Figure 2.

Although the main effect of order was not significant, order did interact significantly with activity of subject $[F(1,12)=5.99, p<.05]$; males investigated active stimuli longer when initially exposed to active, as opposed to inactive, stimuli. This order effect also contributed to a significant interaction of order $\times$ activity $\times$ sex $[F(1,12)=9.31, p<.05]$, since a similar order effect on female investigation was not apparent.

As in Experiment 2, mean investigation time by females was greater for active than for inactive males, but this difference was not significant $(p>.05)$. Investigation by males of inactive stimulus animals 


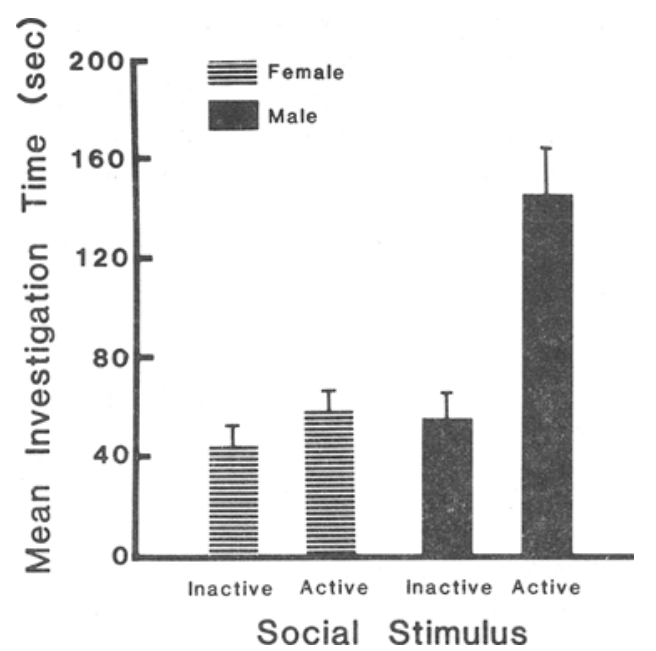

Figure 2. Means and standard errors of investigation times by male and female groups exposed to active and inactive mature male castrates.

did not differ significantly from investigation by females of inactive or active stimulus animals. Investigation by males of active stimulus animals was significantly longer $(p<.01)$ than that of inactive stimulus animals and significantly longer $(p<.01)$ than that by females of active or inactive stimulus animals.

The results confirm the hypothesis and support the conclusion that activity of the social stimulus animal has a distinct influence on promoting the persistence of social investigation by male subjects and a nonsignificant influence on persistence of social investigation by female subjects. Combined results of Experiments 2 and 3 suggest that male and female castrates are essentially equivalent in eliciting investigative behavior from male and female subjects.

\section{GENERAL DISCUSSION}

The present experiments demonstrate that mobility of a novel stimulus animal contributes to social attractiveness and more so to males than to females. Normal movement of a rat seems to have unique dynamic qualities that are shared by conspecifics and are probably associated with former social experience (Hill, 1978; Latané, Joy et al., 1972). Alberts and Galef (1973) found that a normally moving conspecific elicits more aggressive behavior in laboratory-bred, mature male offspring of wild-trapped rats than does an immobile, anesthetized conspecific. Similarly, Tiefer (1969) reported that more active estrous females receive more intromissions and ejaculations than do less active estrous females when multiple receptive females are exposed to a single male. Thor and Flannelly (1978) found that anosmic males are fully capable of identifying and copulating with a single estrous female in a group of nonestrous females, presumably due to nonolfactory soliciting behaviors associated with distinctive movements (hopping, darting, head vibration). When sexually experienced anosmic males are paired with each other, they engage in reciprocal homosexual mounting, apparently sustained by mutual hopping and darting movements (Thor, 1980a). Thus, considerable and varied evidence attests to the importance of normal movement in the initiation and maintenance of social interaction.

The present results confirm and extend the findings of Latané and his associates (Latané, Joy, et al., 1972) indicating that a primary source of social attraction is intimately associated with the dynamic quality of movement and responsiveness. The present experiments also suggest that the sexually dimorphic nature of social investigation in the rat is largely influenced by movement. Prior work indicating a direct relationship in persistence of social investigation to gonadal testosterone or its metabolites (Thor, 1980b) may also be relevant to sex differences in movement perception; that is, testosterone may influence social attractiveness by modulation of the perception of stimuli that change in their spatial configuration. However, Latané and Glass (1968) have shown that a moving object is no more attractive than a stationary object and that a novel object is less attractive than a novel rat. Therefore, stimuli such as odor, warmth, size, sound, and texture of a conspecific must interact, in concert with movement, to provide an attractive complex of social stimulation.

\section{REFERENCES}

Alberts, J. R., \& Galef, B. G. Olfactory cues and movement: Stimuli mediating intraspecific aggression in the wild Norway rat. Journal of Comparative and Physiological Psychology, $1973,85,233-242$.

ВеАсн, F. A. Sexual attractivity, proceptivity, and receptivity in female mammals. Hormones \& Behavior, 1976, 7, 105-138.

Beatty, W. W. Gonadal hormones and sex differences in nonreproductive behaviors in rodents: Organizational and activational influences. Hormones \& Behavior, 1979, 12, 112-163.

Brown, R. E. Mammalian social odors: A critical review. In J. S. Rosenblatt, R. A. Hinde, C. Beer, \& M. Busnel (Eds.), Advances in the study of behavior (Vol. 10). London: Academic Press, 1979.

CArr, W. J. Pheromonal sex attractants in the Norway rat. In L. Krames, P. Pliner, \& T. Alloway (Eds.), Advances in the study of communication and affect (Vol. 3). New York: Plenum Press, 1974.

Carr, W. J., Demesquita-Wander, M., Sachs, S. R., \& MAConi, P. Responses of female rats to odors from familiar vs. novel males. Bulletin of the Psychonomic Society, 1979, 14, 118-120.

Carr, W. J., Hirsch, J. T., \& Balazs, J. M. Responses of male rats to odors from familiar vs. novel females. Behavioral and Neural Biology, 1980, 29, 331-337.

HiLl, W. F. Effects of mere exposure on preferences in nonhuman mammals. Psychological Bulletin, 1978, 85, 1177-1198.

LATANÉ, B., \& GLAss, D. C. Social and nonsocial attraction in rats. Journal of Personality and Social Psychology, 1968, 9, 142-146. 
LAtané, B., \& Hothersall, D. Social attraction in animals. In P. C. Dodwell (Ed.), New horizons in psychology II. Harmondsworth, England: Penguin Books, 1972.

Latané, B., Joy, V., Meltzer, J., Lubell, B., \& Cappell, H. Stimulus determinants of social attraction in rats. Journal of Comparative and Physiological Psychology, 1972, 79, 13-21.

Latané, B., Nesbitt, P., Eckman, J., \& Rodin, J. Long- and short-term social deprivation and sociability in rats. Journal of Comparative and Physiological Psychology, 1972, 81, 69-75.

MEANEy, M. J., \& Stewart, J. Environmental factors influencing the affiliative behavior of male and female rats (Rattus norvegicus). Animal Learning \& Behavior, 1979, 7, 397-405.

SACHS, B. D., \& BARfield, R. J. Functional analysis of masculine copulatory behavior in the rat. In J. S. Rosenblatt, R. A. Hinde, E. Shaw, \& C. Beer (Eds.), Advances in the study of behavior (Vol. 7). New York: Academic Press, 1976.
THOR, D. H. Reciprocal homosexual mounting behavior in paired anosmic male rats. Psychological Reports, 1980, 47, 349-350. (a)

Thон, D. H. Testosterone and persistence of social investigation in laboratory rats. Journal of Comparative and Physiological Psychology, 1980, 94, 970-976. (b)

Thor, D. H., \& Flannelly, K. J. Sex-eliciting behavior of the female rat: Discrimination of receptivity by anosmic and intact males. Behavioral Biology, 1978, 23, 326-340.

TiEfER, L. Copulatory behavior of male Rattus norvegicus in a multiple-female exhaustion test. Animal Behaviour, 1969, 17, 718-721.

(Manuscript received January 23, 1981 revision accepted for publication May 4, 1981.) 